\title{
Indoor monitoring of Scrovegni Chapel Crypt
}

\author{
Paolo Bison ${ }^{1}$, Alessandro Bortolin ${ }^{1}$, Gianluca Cadelano $^{1}$, Giovanni Ferrarini ${ }^{1}$, Fabio Peron ${ }^{2}$, Piercarlo Romagnoni ${ }^{* 2}$ and \\ Antonio Stevan ${ }^{3}$ \\ ${ }^{1}$ CNR - ITC, Corso Stati Uniti, 4 - 35100 Padova (I) \\ ${ }^{2}$ University IUAV of Venezia, S. Croce $191-30100$ Venezia (I) \\ ${ }^{3}$ SYNCRO srl, via Portello, 91 - 35129 Padova (I)
}

\begin{abstract}
The indoor microclimate of the Scrovegni Chapel in Padova (Italy) was analysed first in the '80s. The early study operates in the best way for what concerns the choice of measurement devices and their positioning. Starting from 1995 a Scientific-technical Board coordinates the various initiatives commissioned for the surveys of a conservation of the Scrovegni building structures and for the preservation of frescos. However only during the last ten years, the activities of the Board have been addressed also on the study of the hypogeal environments under the Chapel and in the external environment around it in order to prevent possible damage due to the presence of water which frequently submerges the floor and part of the vertical structures of the crypt (perimeter walls and brick partitions). The investigations have been therefore extended to the crypt. The present work reports the preliminary results of the cyclical survey campaign launched last year and still ongoing: passive thermographic techniques (non-invasive and non-destructive) have been used for the identification and the investigation of the relationship between the boundary seasonal thermohygrometric conditions and the rainfall variations and other exogenous phenomena related to the complex water system of the area on which the Scrovegni Chapel stands.
\end{abstract}

\section{Introduction}

For the purposes of preservation, the knowledge of environmental conditions near the artifacts is fundamental and the knowledge should refer to a sufficiently large period of time. In fact, it is necessary to detect all changes in the medium and long term, indispensable for defining a reliable climatic history of the artwork, which describes not only the variation of the boundary conditions, but also the management of the environment and installations and the influence of visitors.

This methodology was tested inside the Scrovegni Chapel starting from ' 80 s when the first indoor climate campaign was proposed by the Municipality [1]. After 20 years, it was possible to test the management of the installed HVAC system during the first years of operation and to analyse the answers of the environment in relation to the adjustment of the parameters of the HVAC plant [2].

The HVAC system has fully satisfied the main characteristic of operation requested, specifically the conditions of air temperature and humidity between CTA (Adjacent Technical Room) and Chapel, but resorting to some action to change the control parameters. The comparison with the data obtained before the restoration allowed to propose that it was possible to effectively control the indoor thermo-hygrometric parameters, especially during summer period $[2,3]$. The measurements results confirmed the ability of the system to control the microclimate inside the desired range of values; air velocity measures, made punctually in some indoor points, have also detected the absence of turbulence or range of values allowing to accelerate transport phenomena and thermal mass.

The approach has made it possible to detect the importance of heat transfer by radiation as well as exchanges of mass (water vapor) between the indoor air and wall surfaces. As consequence, the monitoring campaign covered the period September 1992 - August 1993 before a preliminary restoration conducted by the Central Institute of Restoration in 1994. Starting from 1995 a Scientific-technical Board coordinates the various initiatives commissioned for the surveys of a conservation of the Scrovegni building structures and for the preservation of frescos $[4,5,6]$.

In the last years the preservation activities have concentrated on the study of the hypogeal environments under the Chapel and in the external environment in order to prevent possible damage due to the presence of water, often present in significant quantities, which frequently submerges the floor and part of the vertical structures of the crypt (perimeter walls and brick partitions).

The investigations have been therefore extended to the crypt: the analysis of the indoor microclimate and the use of IR thermography can help to identify the mechanisms responsible for the presence of water. Secondarily, IR thermography would allow to locate and identify possible elements present in the walls of the crypt hidden from view because covered by layers of surface finish, with

*Corresponding author: piercarlo.romagnoni@iuav.it 
particular interest to the back wall, located at the presbytery area, near the entry of the hypogeum.

At the same time, works have been planned and commissioned for the safety of the plaster and the pictorial film of the crypt through the use of acrylic resin, in addition to the consolidation for the restoration of the cohesion of the masonry support and of the preparatory layers. The execution of essays (coring) and investigations on the head walls of the crypt was also planned.

\section{THE SCROVEGNI CHAPEL MICROCLIMATE: A SHORT OVERVIEW ON RECENT STUDIES AND INTERVENTIONS}

The Scrovegni Chapel (Figure 1 and 2) indoor microclimate was analysed during the ' 80 s [1]. This early study operates in the best way for what concerns the choice of tools and their positioning. Thus it was possible to well operate before the start of any work of restoration, noting values of surfaces temperature, vertical and horizontal gradients of air temperature and relative air humidity.

The approach has made it possible to detect the importance of heat transfer by radiation as well as exchanges of mass (water vapor) between the indoor air and wall surfaces.

The heating of the wall surfaces, and the consequent evaporation of water, is mainly due to solar radiation. During the night period, as a consequence of the cooling down the direction of flow of mass changes, while particulates and dust can penetrate the surface. possibility of condensation of water vapour. The process of migration of water vapor can be an important source of damage: the water dissolves the salts within the pores of the material constituting the wall, and then transports the soluble salts to the surface where, due to evaporation, the salt crystallizes. The consequence is an inevitable mechanical stress of the painted surfaces.

The presence of water in the walls had been detected several years ago: both came from roof leaks, either by capillary rising from that condensation of steam when the surface temperature falls below the value of the dew point temperature [4]. The salts also often have a hygroscopic behaviour: for this reason, as early as 1993, a protective outer layer was applied [5].

Other studies of greater consistency on the structure have been made during the last ten years. The air quality measurements obtained between 1977 and 1978 have revealed the presence of sulfation on the surfaces due to particles of $\mathrm{SO}_{2}$ from the front door; higher values of particulate matter were measured starting from years seventies until the nineties. The surface of the main frescos surface (The Judgement) presented efflorescence until before the restoration works and also recently measured the presence of NOx [5].

The state of preservation of the frescoes at the end of the $90 \mathrm{~s}$ was such as to require a particular attention to the indoor microclimate and its management in order to have recourse, if necessary, to propose a HVAC installation. A Scientific-technical Board was created in 1995 to coordinate the various initiatives and assess the possible interventions.

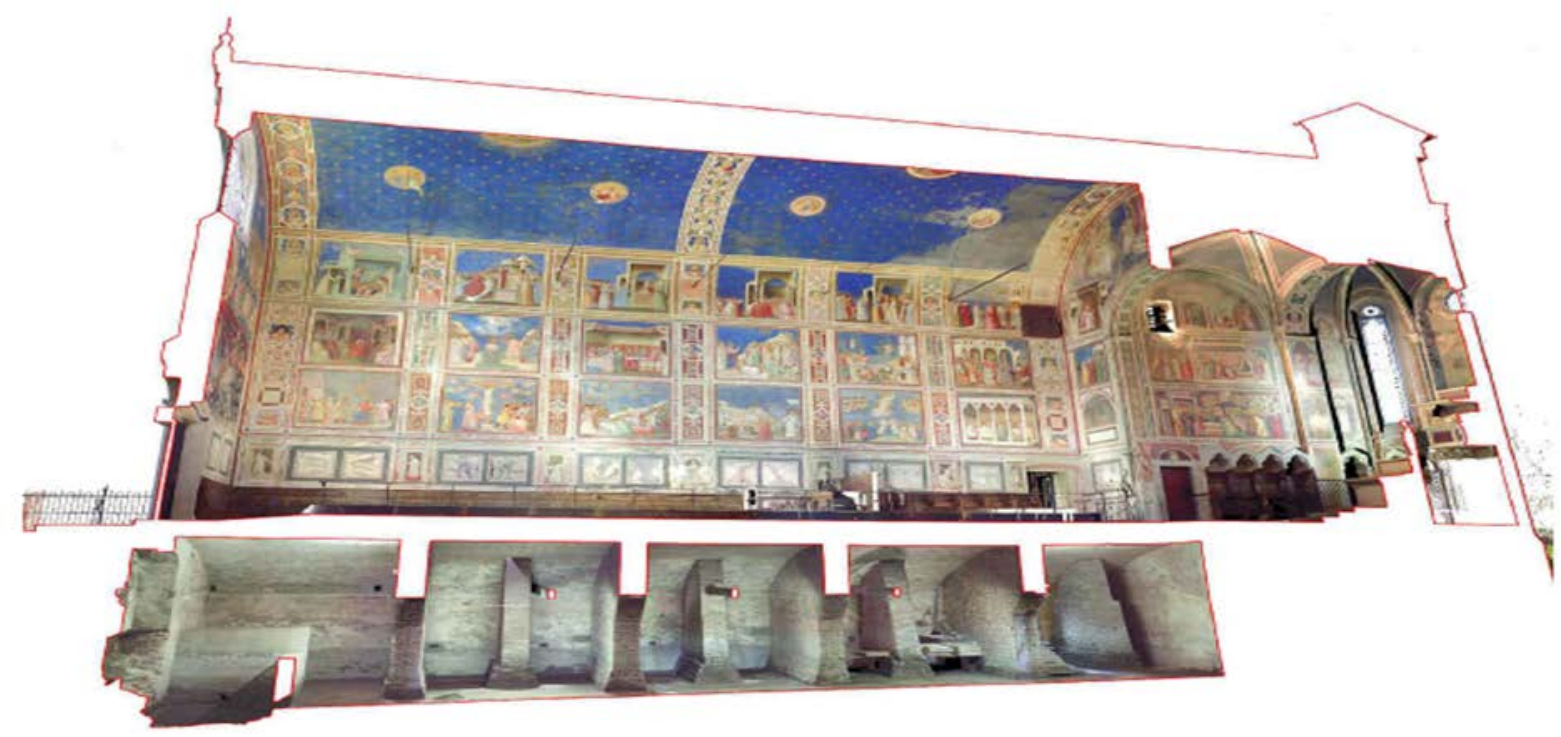

Fig. 1. The Scrovegni Chapel with the crypt

A first monitoring covered the period September 1992 - August 1993 [3] before a preliminary restoration conducted by the Central Institute of Restoration in 1994: measures air temperature, humidity and surface temperatures collected during this period made it possible to characterize the internal microclimate, evaluate the thermal exchanges with the external environment and the
The Institute of Technical Physics (University of Padova) was commissioned to investigate the internal microclimate and to assess, on the basis of measurements of environmental parameters, such as the implications and requirements which could characterize an air treatment system [6]. 
Restoration works were planned in 2001, closed in 2002 and carried out by the following organisations: ICR scientific laboratories, an international committee of experts on wall painting restoration, an interdisciplinary commission for the restoration of the Scrovegni Chapel, composed of technical experts from the City Council and the Ministry for Cultural Heritage, as well as university experts.

Further interventions were planned in 2016 and a proposal for the studies of the indoor microclimate of the Scrovegni's Crypt was addressed to the Board at the end of the same year. The new measurements campaign starts in Novembrer 2017 and it is still ongoing.

\subsection{The InfraRed Thermography Analysis}

The analysis were proposed with the aim of assessing the feasibility of a non-destructive survey, based mainly on infrared thermography, for diagnostic purposes.

The aims are to identify the possible degradation mechanisms associated with the presence of water, often in large quantities, that frequently submerges the floor and part of the vertical structures of the crypt (perimeter walls and brick walls) before the installation of a pumping system.

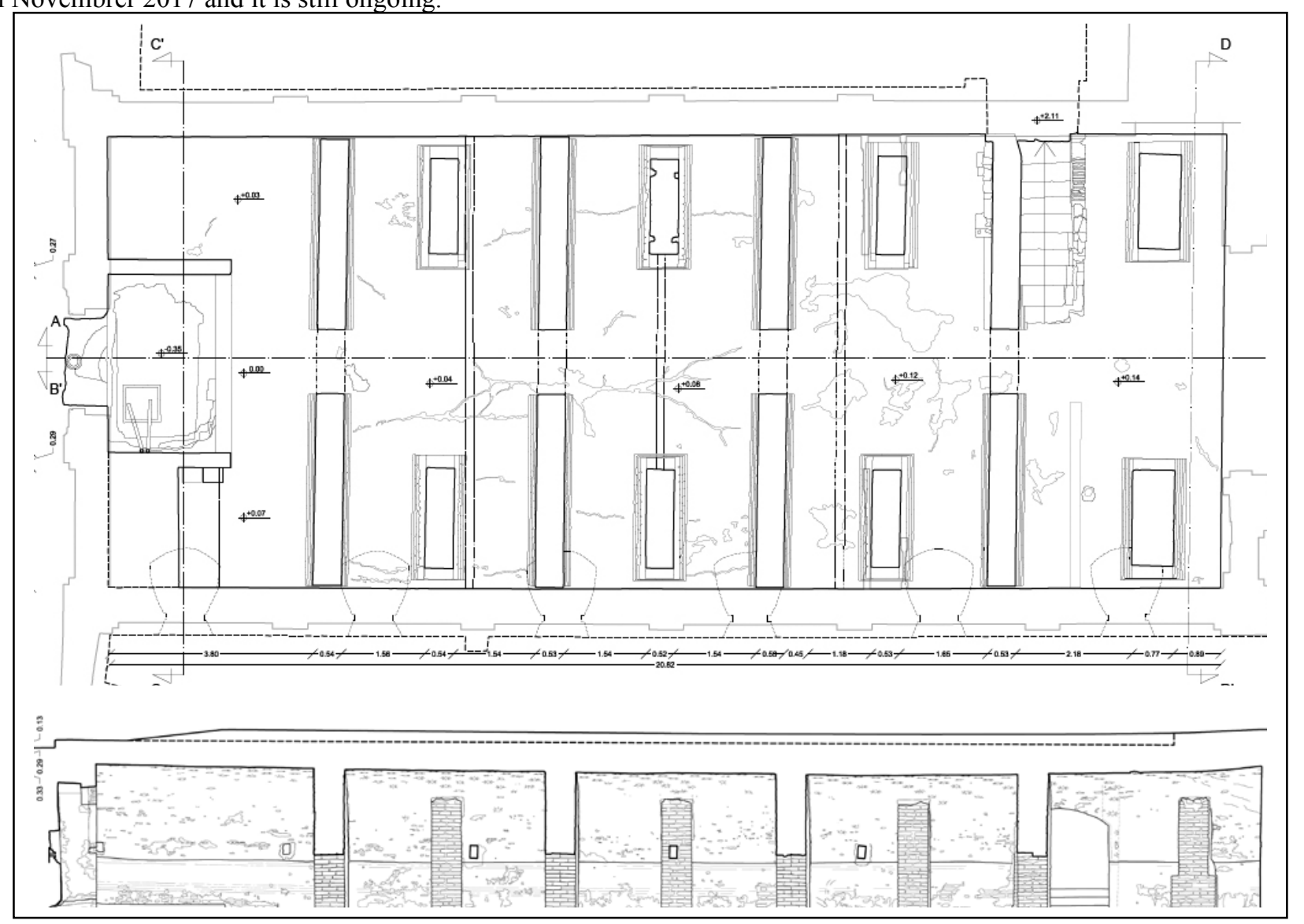

Fig. 2. The Scrovegni Chapel. The crypt: a) the plan; b) the section

\section{THE MEASUREMENTS CAMPAIGN}

The main scope of the first campaign of experimental investigations was the evaluation of the consistency of the structures, in particular as regards the foundational part.

The campaign was carried out in order to determine the main properties of the materials and the construction techniques. The tests performed were of a character weakly destructive (coring), and have been summarized by others of totally non-destructive features (endoscopies). The tests conducted also allowed to define the shooting positions for IR thermography.
The IR images was collected in December 2017; the recorded data for air temperature was $6,5^{\circ} \mathrm{C}$ and $\mathrm{RH}$ was $71 \%$ (average values during the measurement time)

Secondly, we intend to locate and identify possible elements present in the walls of the crypt hidden from view because covered by layers of surface finish, with particular interest to the wall, located at the presbytery area, near the entrance to the hypogeum. Infrared thermography is a non-destructive and non-invasive technique that allows visualization of surface temperatures [7].

From the analysis of the distribution and the temporal evolution of the superficial temperatures it is possible to obtain information that can be interesting for a better knowledge of the historical buildings and that can be correlated with their state of conservation or degradation. 
Starting from the basic data, the numerous thermal imaging techniques used in literature allow us to highlight the physical phenomena that are the cause of a particular temperature distribution, such as the presence of humidity, decohesion or detachment of the surface layer, inhomogeneity thermophysical parameters of the structure $[8,9,10]$.

Infrared thermography also makes it possible to evaluate the presence and the location of any hidden structures, allowing the visualization of the wall texture and the definition of the cracking pattern [11]. These investigations have already been successfully carried out in the past by the Chapel, together with microclimatic evaluations [12]. Table 1 shows the IR camera characteristics.
Table 1. IR camera characteristics

\begin{tabular}{|l|l|}
\hline Focal length & $\begin{array}{l}131 \mathrm{~mm}, 7^{\circ} \text { fov; } 38 \mathrm{~mm}, 24^{\circ} \\
\text { fov; } 19 \mathrm{~mm}, 45^{\circ} \text { fov }\end{array}$ \\
\hline $\begin{array}{l}\text { Spatial resolution } \\
\text { (IFOV) }\end{array}$ & $0.65 \mathrm{mrad}$ with standard optics \\
\hline $\begin{array}{l}\text { Thermal sensitivity/ } \\
\text { NETD }\end{array}$ & $<30 \mathrm{mK}$ when $+30^{\circ} \mathrm{C}$ \\
\hline Image frequency & $\begin{array}{l}30 \mathrm{~Hz}(60 / 120 \mathrm{~Hz} \text { in window } \\
\text { mode) }\end{array}$ \\
\hline Focus & $\begin{array}{l}\text { Automatic or manual zoom; } 1-8 \\
\mathrm{x} \text { continuous, digital zoom, } \\
\text { panning mode }\end{array}$ \\
\hline $\begin{array}{l}\text { Detector; spectral } \\
\text { range of sensitivity }\end{array}$ & $\begin{array}{l}\text { Uncooled microbolometer 7.5- } \\
13 \mu \mathrm{m}\end{array}$ \\
\hline Thermal image size & $640 \mathrm{x} 480$ pixel \\
\hline
\end{tabular}

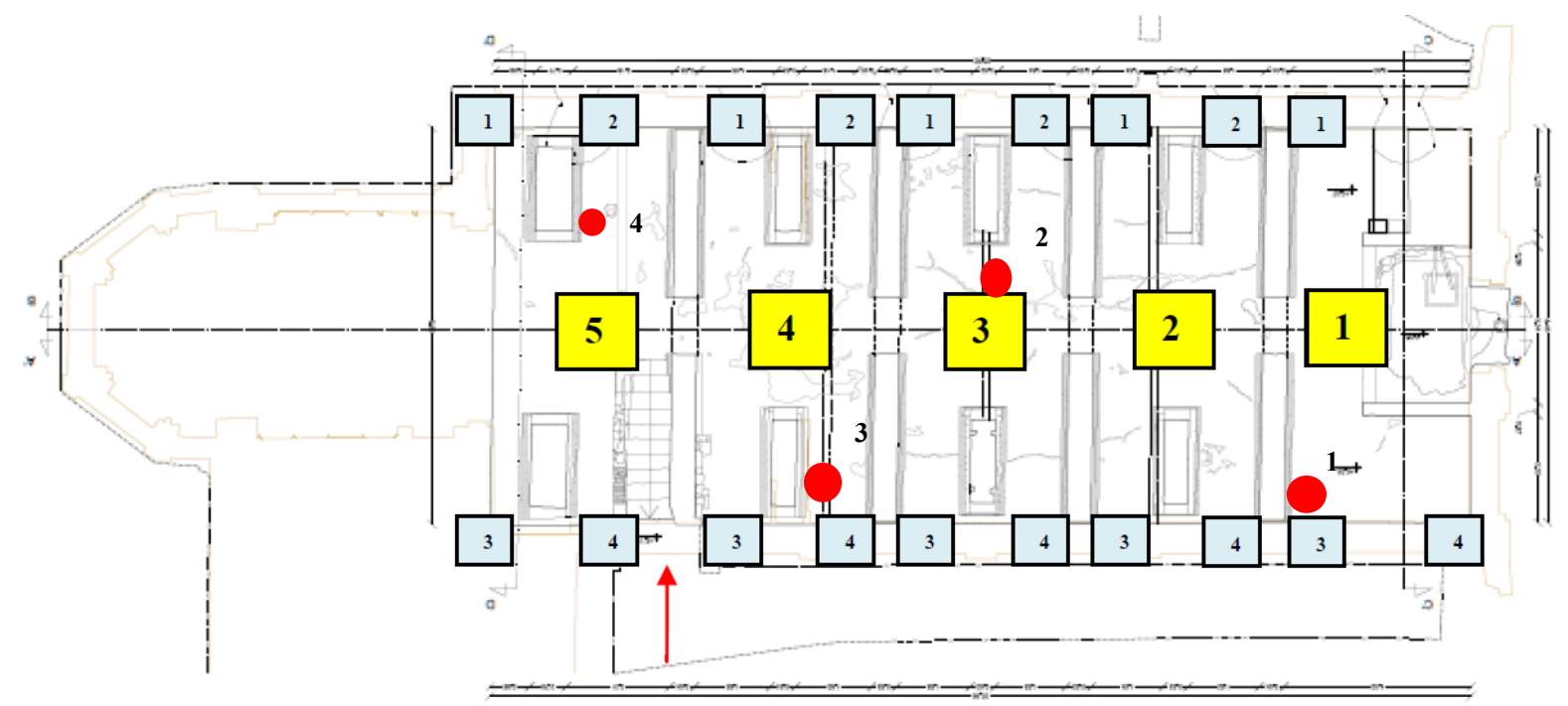

Fig. 3. IR shots and indoor climate probes, points of measurements. Yellow boxes represent the IR camera positions, and light blue boxes represent the areas on the walls object of IR shots; red dot represent the indoor air temperature and $\mathrm{RH}$ probes positions.

All the thermographic acquisitions, however noninvasive and non-destructive, were conducted with a "passive" technique, ie without the use of thermal sources or forced ventilation. In relation to the purposes of the diagnostic campaign, the following tests were performed:

- n. 19 thermographic acquisitions of masonry, selecting up to four shots (light blue boxes in figure 3 ) for each of the five positions of the IR camera (yellow boxes in figure 3) aimed at determination of the thermal and hygroscopic conditions of the perimeter walls and the partitions;

- n. 2 vertical panoramic thermographic acquisitions aimed at evaluating the distribution of the surface temperature and humidity when the height changes with respect to the walking surface;

- $n .1$ thermographic acquisition of the back wall at the designated presbytery area to the identification of thermal anomalies, or portions of masonry having a surface temperature with respect to the surrounding areas and a particular distribution morphology.

Figure 3 shows the shooting views and recovery points.
From the IR images it is possible to deduct a modest presence of water on the floor and it was possible to verify the existence of evaporative fronts compatible with the presence of humidity inside the walls that make up the clay septa (see example in Figure 4).

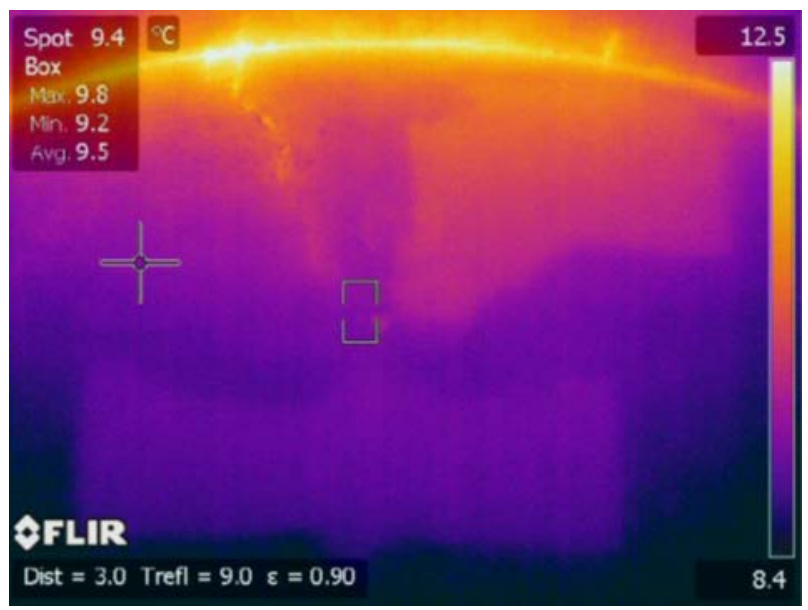

Fig. 4. IR image from standing point 5 to wall area 3. 
In addition, a thermal inhomogeneity between the floor and the vertical walls has been observed (in particular the septa), particularly evident in the areas where the elements are joined (see, for example, the point of recovery 2, Figure 5).

It could be interesting also to analyse the wall near the entrance to the crypt, where other active thermographic techniques could be applied (short heating of a few degrees centigrade) which, by increasing the thermal contrast on the surfaces, would make it possible to search for further hidden structures.

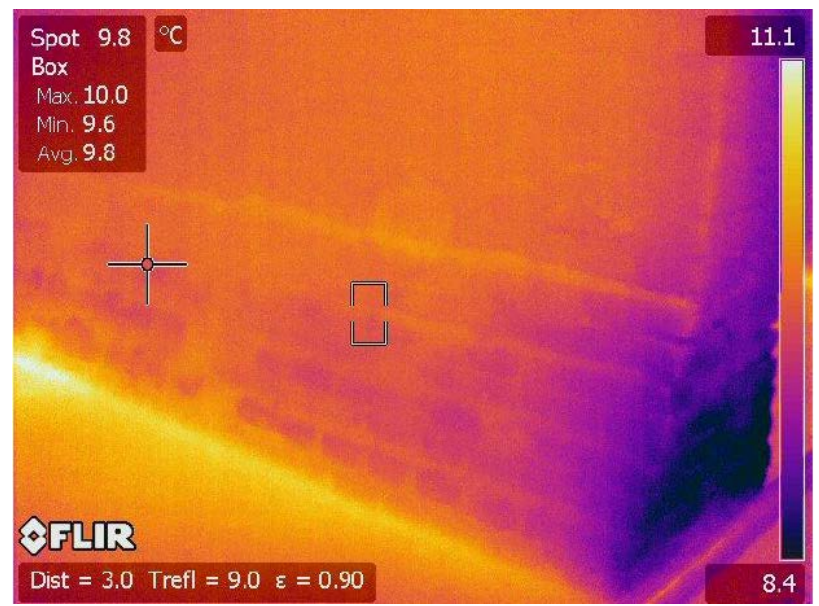

Fig.5. IR image from standing point 2 to area 3.

\subsection{The indoor microclimate}

The indoor microclimate has been measured by means of air temperature and relative humidity probes. The probes were placed as showed in Figure 3. Two of the four probes allow to measure also the surface temperatures.

The probes position is summarized as follows:

Position 1: entrance $-2 \mathrm{~m}$ height

Position 2: second room $-2 \mathrm{~m}$ height. This probe is placed in the separation wall and the surface temperature of this wall is also measured

Position 3: third room $-3,0 \mathrm{~m}$ height

Position 4: last room. The surface temperature of the last separation wall is also measured

The presence of 6 windows already open (see Figure 2 ) suggests that the air ventilation can be consistent and the indoor and outside condition can be very similar.

The time step for data collection was fixed every 15 minutes. The characteristics of the probes are in Table 2 .

Table 2. Characteristics of relative humidity, air and surface temperatures probes

\begin{tabular}{|l|l|l|}
\hline & Temperature & Relative Humidity \\
\hline range & $-20^{\circ}$ to $70^{\circ} \mathrm{C}$ & $5 \%$ to $95 \%$ \\
\hline accuracy & $\begin{array}{l} \pm 0.35^{\circ} \mathrm{C} \text { from } 0^{\circ} \mathrm{C} \\
\text { to } 50^{\circ} \mathrm{C}\end{array}$ & $\begin{array}{l} \pm 2.5 \% \text { from } 10 \% \text { to } \\
90 \%\end{array}$ \\
\hline resolution & $0.03^{\circ} \mathrm{C}$ at $25^{\circ} \mathrm{C}$ & $0.05 \% \mathrm{RH}$ \\
\hline drift & $0.1^{\circ} \mathrm{C} /$ year & $\begin{array}{l}<1 \% \text { per year typical; } \\
\mathrm{RH} \text { hysteresis } 1 \%\end{array}$ \\
\hline
\end{tabular}

Figure 6 shows the recorded values of indoor air temperatures as measured in the 4 positions starting from middle of December 2017 until April 2018. Figure 7 shows the recorded values during a 10 days period (February $24^{\text {th }}$ to March $6^{\text {th }}, 2018$ ): more details on different values are more evidenced

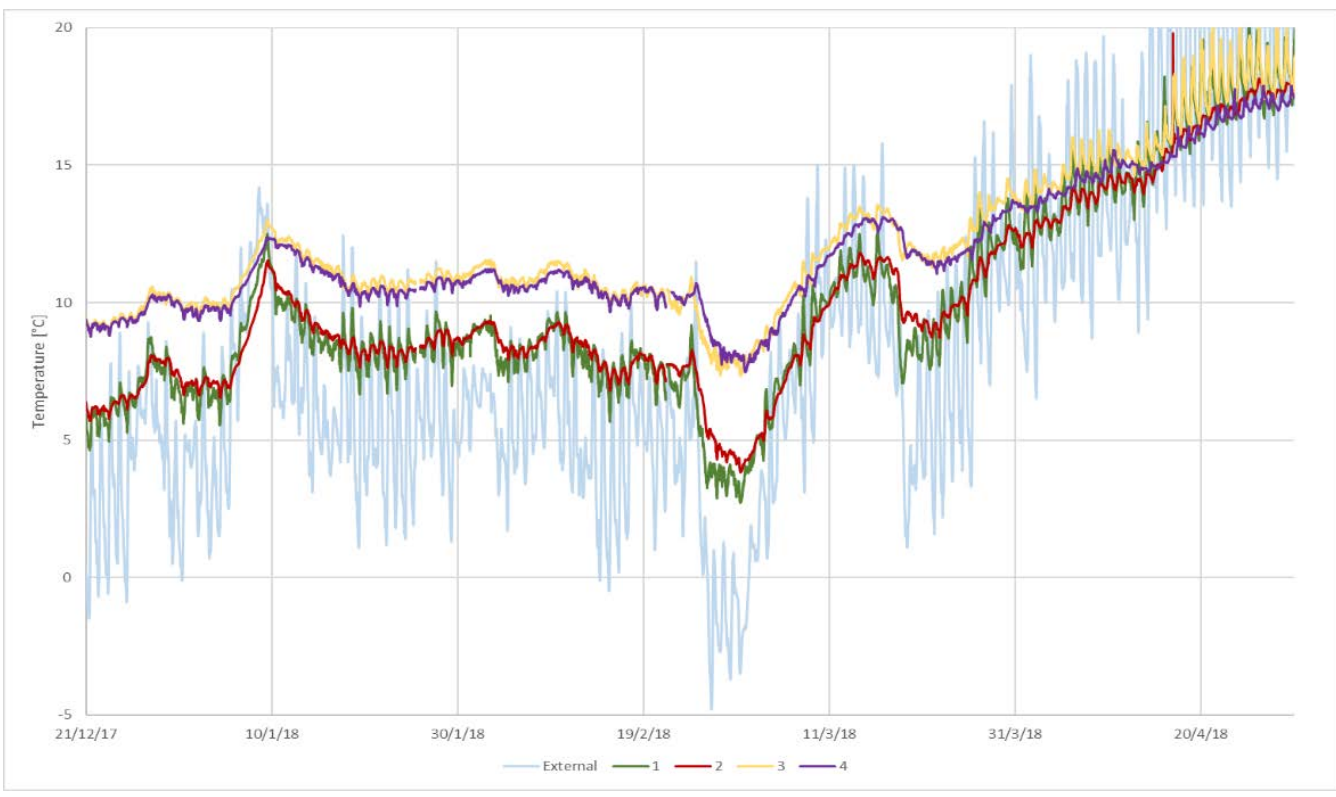

Fig. 6. Indoor and outdoor air temperatures in the 4 different position from middle of December 2017 to middle of April 2018. 


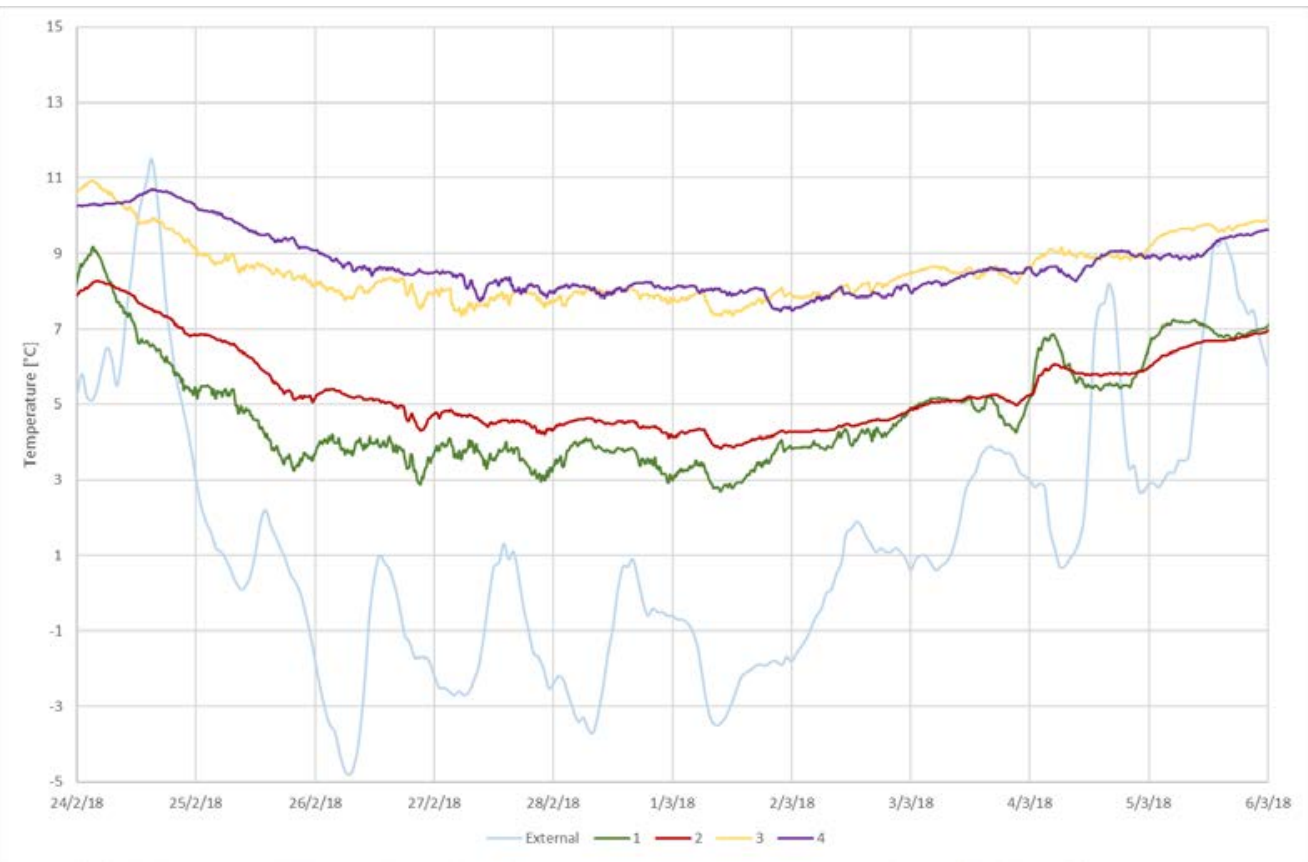

Fig. 7. Indoor and outdoor air temperatures from February $24^{\text {th }}$ to March $6^{\text {th }} 2018$

In general relative humidity was high during the analysed period. In the area around point 2 , more internal, the relative humidity was higher, between $75 \%$ and $95 \%$. In the area around point 4 , more connected with the external environment, humidity values were a bit lower.

Table 3 presents maximum, minimum and mean values of the collected data for each position

Table 3. Temperatures and RH variations

\begin{tabular}{|l|c|c|c|}
\hline & $\begin{array}{c}\text { Air } \\
\text { temperature } \\
{\left[{ }^{\circ} \mathrm{C}\right]}\end{array}$ & $\begin{array}{c}\mathrm{RH} \\
{[\%]}\end{array}$ & $\begin{array}{c}\text { Surface } \\
\text { temperature } \\
{\left[{ }^{\circ} \mathrm{C}\right]}\end{array}$ \\
\hline Position 01 & \multicolumn{2}{|c|}{} \\
\hline maximum & 25,8 & 94,5 & - \\
\hline minimum & 4,1 & 51,6 & - \\
\hline mean & 15,8 & 80,9 & - \\
\hline Position 02 & \multicolumn{3}{|l|}{} \\
\hline maximum & 25,4 & 93,5 & 25,8 \\
\hline minimum & 3,8 & 52,6 & 3,0 \\
\hline mean & 15,7 & 79,9 & 15,3 \\
\hline Position 03 & \multicolumn{3}{|l}{} \\
\hline maximum & 27,6 & 95,8 & - \\
\hline minimum & 7,3 & 47,4 & - \\
\hline mean & 15,5 & 81,9 & - \\
\hline Position 04 & \multicolumn{3}{|l}{} \\
\hline maximum & 23,8 & 93,8 & 23,8 \\
\hline minimum & 7,5 & 56,2 & 7,3 \\
\hline mean & 14,8 & 82,9 & 14,7 \\
\hline
\end{tabular}

Internal air temperature follows the external oscillations as a consequence of the high level of connection between the underground environment with the external. The comparison between the air temperature and the wall surface temperature indicate a strict correlation with a little delay on wall behaviour and more pronounced maximums and minimums on the air temperature curves.

\section{DISCUSSION AND CONCLUSIONS}

Despite the underground position of the Scrovegni Chapel Crypt the IR analysis found a modest presence of water on the floor and some evaporative fronts quite low on the walls. In general air relative humidity was high during the analysed period but also in this case taking into account the fact that the crypt is an underground environment the measured values are not so impressive.

Further information can be obtained through the microclimate analysis still in progress and by a planned campaign of cyclic surveys using active thermographic techniques with the use of artificial forced ventilation in order to increase the evaporative effect of wet areas [13]. This technique improves identification and investigation of the relationship of the structures with the boundary conditions occurring as a result of seasonal thermohygrometric and seasonal changes or in relation to other exogenous phenomena related to the complex water system of the area on which the Scrovegni Chapel stands. In this way the hygrometric state of a surface is defined without resorting to gravimetric measures (invasive and destructive, such as the UNI 11085 standard [14]), introducing a parameter called STI (Saturation Thermal Index), which allows to evaluate how much each point of the wall is close to or less than the saturation condition. 


\section{REFERENCES}

[1] D. Camuffo, P. Schenal, Indoor microclimate of the Scrovegni Chapel: mass and thermal exchanges between surfaces and idoor air (in Italian), Bollettino d'Arte, Edizione Speciale, Istituto Poligrafico e Zecca dello Stato, 107-209, 1982.

[2] C. Bonacina, P. Baggio, F. Cappelletti, P. Romagnoni, A.G. Stevan, The Scrovegni Chapel: The results of over 20 years of indoor climate monitoring, Energy and Buildings, 95, 144 -152, 2015.

[3] SYNCRO, The Scrovegni Chapel in Padova Continuous monitoring of indoor thermal parameters (in Italian), Report for Padova Municipality,1993.

[4] V. Fassina, Moisture problems inside the wall and facade protection (in Italian), Proceedings of the workshop "La Cappella degli Scrovegni - Indagini, restauri, interventi" - February $25^{\text {th }}$, Stampa Arti Grafiche Padovane, 37 - 41, 1998.

[5] M. Marabelli, Measurements and problems by pollutions and soluble salts (in Italian), Proceedings of the workshop "La Cappella degli Scrovegni - Indagini, restauri, interventi" - February $25^{\text {th }}$, Stampa Arti Grafiche Padovane, 48 - 53, 1998.

[6] C. Bonacina, P. Baggio, M. Mariotti, P. Romagnoni, Indoor microclimate management of the Scrovegni Chapel (in Italian), Proceedings of the workshop "La Cappella degli Scrovegni - Indagini, restauri, interventi" - February $25^{\text {th }}$, Stampa Arti Grafiche Padovane, 60 $64,1998$.

[7] X. Maldague, Theory and Practice of infrared technology for non-destructive testing, Wiley, 2001.

[8] A. Bortolin, G. Cadelano, G. Ferrarini, P. Bison F. Peron, X. Maldague, High resolution survey of buildings by lock-in IR thermography, SPIE vol. 8705, 1-7, 2013.

[9] E. Grinzato, C. Bressan, F. Peron, P. Romagnoni, A.G. Stevan, Indoor climatic conditions of ancient buildings by numerical simulation and thermographic measurements, SPIE vol. 4020, 314-323, 2000.

[10] E. Grinzato e M. Strada, F. Peron, Moisture monitoring of historical buildings by long period temperature measurements, SPIE vol. 3700, 471-482, 1999.

[11] E. Grinzato, N. Ludwig, G. Cadelano, M. Bertucci, M. Gargano, P. Bison, Infrared thermography for moisture detection: a laboratory study and in-situ test, Materials Evaluation, 69 (1), 97-104, 2011.

[12] E. Grinzato, C. Bressan, S. Marinetti, P.G. Bison, C. Bonacina. Monitoring of the Scrovegni Chapel by IR thermography: Giotto at infrared, Infrared Physics \& Technology, Volume 43, Issues 3-5, 165-169, 2002.

[13] P. Bison, F. Agrosì, A. Bortolin, G. Cadelano, G. Ferrarini, E. Grinzato, Water content classification in porous material by periodic forced ventilation, Proceedings of the 11th QIRT International Conference on Quantitative InfraRed Thermography, Naples (Italy), 2012.

[14] UNI 11085, Cultural heritage - Natural and artificial stone materials - Determination of water content: Weight method, Italian Bureau of Standard,2003. 